\title{
Los vientos que soplaron en Santo Domingo y la evangelización de la cultura
}

\author{
Jon Sobrino \\ Centro de Reflexión Teológica, \\ San Salvador, EI Salvador.
}

\section{Santo Domingo como acontecimiento}

En este artículo queremos reflexionar sobre Santo Domingo, desde una perspectiva precisa, como acontecimiento con un polencial evangelizador de la cultura. Con esto no negamos la necesidad de analizarlo desde otras perspectivas y, en concreto, de analizar el texto que han producido los obispos, pero nos concentramos aquf en el acontecimento de Santo Domingo porque creemos que, en cuanto acontecimiento, posee ya su propio significado y su propia capacidad de configurar, de una u otra manera, la realidad de nuestro mundo. Esto es lo que analizaremos en detalle más adelante, pero hagamos antes unas reflexiones para mejor comprender el lítulo y la finalidad de este artículo.

La primera reflexión es que, en cuanto acontecimiento, Santo Domingo cstá hecho de muchos elementos, los más importantes de los cuales fueron las tareas de preparación, la mayor o menor participación en ello de todos los miembros de la Iglesia latinoamericana, los textos producidos en ese período, las medidas y reacciones del Vaticano, y, por supuesto, todo lo ocurrido en Santo Domingo: presencia y discursos del papa, presencia de los obispos, sus declaraciones y tomas de postura personales, ausencias umbién y las razones para ello, discusiones, tensiones y acuerdos en el aula, celebraciones, las diversas redacciones del texto, el texto final, su interpretación y su recepción...

Todos estos elementos convergen en un texto, pero en sí mismos son más que el texto escrito o, si se quiere, son un texto in actu que puedc llegar incluso a tener más impacto que el aprobado por el papa. Este impacto proviene de lo que se ha dicho y hecho durante todo el proceso, de lo que no se ha dicho y no se hecho y del modo de decirlo y hacerlo. Todo ello hay, pues, que tener en 
cuenta al hablar de Santo Domingo, aunque un elemento pucda tener más rclevancia que otro, de hecho o de derecho. Y todo ello - no sólo cl texto-- es transmitido a la Iglesia y a la socicdad a través de lo que en lenguaje melafórico llamamos "los vientos" que han movido el proceso y, a su vez, los que éste ha desencadenado $-y$ de ahí el título de estas reflexiones. En lo que quercmos insistir es en que tanto o más que los textos de Santo Domingo "estos vientos" son los que inspirarán o no ideales, los que alcntarán o no práclicas y los que configurarán en una u otra dirección la conciencia colectiva.

Esto en realidad no es nada nuevo, pues asi ha ocurrido siempre. Los acontecimientos importantes generan sicmpre un texto y un espíritu - "vientos", literalmentc hablando-, y ambas cosas influyen en la historia. Cada una de ellas lo hace según su especificidad propia, pero pensamos que cuando los acontecimientos son relativamente recientes más influjo tiene en la Iglesia y en la sociedad cl "espíritu" del acontecimiento que el mismo "tex gráfica, más sucle quedar la "música" — siguiendo la meláfora del viento- que la "letra", a no ser por supuesto para los expertos y encargados de analizar y transmitir esa letra.

Por recordar dos acontecimientos de suma importancia, pocos conocen y recucrdan hoy los textos del Vaticano II, pero queda todavia su brisa refrescante. En una Iglesia desencarnada, cerrada sobre sí misma, autoritaria, condenadora de prácticamente todo lo que no fuera clla, angustiada y angusliantc por su visión omnipecaminosa se produjo el milagro, la Iglesia abrí́ puertas y ventanas, sustituyó el miedo por la esperanza, la imposición por el diálogo, el dogmatismo por la honradcz... Deberán analizarse los textos del concilio - obviamente - y puede discutirse hasta la saciedad cuál es su interpretación auténtica, como está ocurriendo ahora de parte y parte. Pero hasla cl día de hoy, más importante que los texlos del concilio, con ser muy importantes, nos parece que lo es su espíritu de honradez, de diálogo, de liberlad, de esperanza, de compasión, de vuelta a Jesús... Esto es, pensamos, lo que precisamente hoy está en discusión en la Iglesia, aunque las batallas se planteen al nivel de interpretación de textos. Y si los textos siguen siendo significativos y dicentes todavía hoy es porque en su tolalidad, aunque unos sean mejores que otros, cstán imbuidos de ese espíritu.

$Y$ algo semejante hay que decir de Medellín. De nuevo, poca gente conoce hoy ya sus textos. Más aún, de entre quienes los conocen no faltan algunos que afirman que, después de todo, Pucbla e incluso Santo Domingo tienen mejores textos que Mcdellín. $Y$ en cicrto sentido no les falta razón. Sin embargo, no creemos que el espiritu de Medellín ha sido superado, y es esc espíritu el que manticne - contra viento y marea, siguiendo la metáfora- lo fundamental: que hay que ir a los pobres de csic mundo, encarnarse en ellos, defenderlos y arricsgar por cllos, denunciar a sus opresores, y que cn todo cllo la Iglesia sc va

Universidad Centroamericana José Simeón Cañas 
haciendo la Iglesia de Jesús, los cristianos se van haciendo seguidores de Jesús y creyentes en el Dios de Jesús.

Medellín es Lodavía - a pesar de textos "anticuados"- el símbolo no superado de la "nueva" evangelización. Su espíritu -y no tal o cual texto- es el que operó el cambio más radical en la Iglesia latinoamericana desde sus inicios y el que operó el milagro de que esa Iglesia, por primera vez en su historia, fuese cristiana y fuese latinoamericana, no una Iglesia evangélicamente aguada e históricamente de importación.

La segunda reflexión previa es de otra índole, pero viene sugerida e incluso exigida por la misma temática central de Santo Domingo: la nueva evangelización, y más específicamente, la evangelización de las culturas. Esto último puede ser comprendido de varias formas: o como inculturación de la fe en las variodas culturas o como configuración de cualquier cultura según valores y formulaciones cristianas. Aquí, sin embargo, queremos enfocar el tema de la evangelización de la cultura desde otra perspectiva.

Por decirlo de forma sencilla, podemos preguntamos qué aire respiramos los humanos, y si éste está purificado o contaminado. Podemos preguntamos si nuestra atmósfera no está transida de mentira y encubrimiento, crueldad e injusticia, hybris y prepotencia, de modo que de antemano - de forma estrucluralla cultura nos inclina al mal, no al bien. Podemos preguntamos si la contaminación está destruyendo la ecología no sólo del cuerpo, sino también la del espíritu. Si esto es así, evangelizar la cultura es también introducir en el ambiente sea cual fuere la explicitación cristiana- honradez, misericordia, gratuidad, justicia, dignidad...

Pues bien, los acontecimientos históricos importantes deben analizarse también desde esta perspectiva, y por ello hay que preguntar si Santo Domingo, cn cuanto acontecimiento, ha evangelizado o no a nuestro mundo, si ha ayudado a purificar o a contaminar el ambiente. Al responder a estas preguntas hay que estar claros, además, en que, como en toda evangelización, tampoco ésta ocurre desde una tabula rasa. Como Jesús, hay que anunciar una buena noticia en presencia de y en contra de malas realidades, hay que anunciar el reino de Dios en presencia de y en contra del antirreino de los ídolos. Al analizar, por tanto, el acontecimiento de Santo Domingo hay que ver si en sí mismo ha evangelizado o no la cultura, el aire que respiramos, y si al hacer una u otra cosa se ha enfrentado con los poderosos. $Y$, repetimos, esto se puede expresar en textos, pero va más allá de ellos.

Desde esta perspectiva vamos a hacemos, con la mayor objetividad posible, la siguiente pregunta: en qué sentido y en qué medida Santo Domingo ha evangelizado o no al mundo en que vivimos, ha facilitado o no poner en práctica las formulaciones de fe que nos exige y los textos que nos ofrece.

Digitalizado por Biblioteca "P. Florentino Idoate, S.J."

Universidad Centroamericana José Simeón Cañas 


\section{Santo Domingo como acontecimiento evangelizador}

\section{Identidad latinoamericana e imposición romana}

En el documento preparatorio llamado Secunda Relatio, elaborado por los obispos latinoamericanos en sus propias diócesis, se puede leer este espléndido texto que bien pudiera fungir como resumen de la novedad, de la identidad y de lo mejor de la Iglesia latinoamericana desde el concilio Vaticano II:

El 24 de marzo de 1980 toda la Iglesia y la opinión mundial se estremecieron con el horrible asesinato del arzobispo de El Salvador, Oscar Arnulfo Romero, quien, celebrando la misa, cayó acribillado a balas, márlir del ministerio episcopal por su función profética.

Casi diez años después, en la misma ciudad de San Salvador, la noche del 16 de noviembre de 1989, scis Padres Jesuilas de la Universidad Centroamericana, junto con dos empleadas de la casa, fueron masacrados a mansalva en su residencia por soldados durante el toque de queda. La noticia de nuevo causó conmoción mundial; cllos murieron por su compromiso sacerdotal y rcligioso con la justicia y el respeto a los derechos humanos y por su opción ministerial con los jóvencs y los pobres.

Estos hechos denotan, junto a muchos otros ejemplos, que nuestra Iglesia en América Latina, durante estas últimas décadas, se ha convertido en una Iglesia de máruires y perseguidos. En la pléyade de mártires asesinados, junto a obispos, saccrdolcs, seminaristas, religiosos y rcligiosas, sc encuentra una gran mayoria de agentes pastorales laicos, campesinos y obrcros; muchos ouros han sido calumniados, sccuestrados, torturados, exiliados.

La novedad histórica de esta persecución la constituye su contexto, pues se realiza en el ámbito del mundo occidental cristiano y por quienes se proclaman defensores de esta cultura y aun de los principios cristianos. Esto sucede porque las diversas idolaurias opresoras del Coninente, denunciadas en Puebla, han percibido una gran amenaza en la Iglesia a partir de Medellín y Puebla, y han tratado de contrarrestarla de diversas formas: con la difusión y financiamiento de sectas que propugnan una rcligiosidad espiritualista y no comprometida, con la propiciación de un cristianismo liberal individualista y también con el ataque directo y la persecución. 
Es así como la Iglesia en la realidad de América Latina, fiel a su fe en el Dios de la vida y a su misión de salvación y liberación, da testimonio en la persccución y el maririo.

Pucs bien, de este significalivo texto no queda ni un pálido eco en el documento linal. Más adelante volveremos a él, pero ahora queremos preguntarnos dónde puede estar la raíz de tan notable ausencia, y en nuestra opinión -más allá de delalles- está en la imposición romana sobre una lglesia latinoamericana que fue adquiriendo identidad propia y evangélica. $Y$ por aqui quercmos comenzar nuestra reflexión.

En todos las sociedades se dan autoritarismos y, visto el mundo como totalidad, también centralismos, con el correlativo sometimiento a las superpotencias. A su vez, otros propician diálogos, actitudes realmente "democráticas" que, en Icnguaje político, se acercarían a las relaciones fratemas que nos pide el evangelio. Pues bicn, también esta problemática se hizo presente in actu - no tanto en la discusión teórica sobre ella - en Santo Domingo y con mayor agudeza que en Medellín y Puebla. El hecho es que a pesar de los desmentidos y eufernismos existió no sólo diversidad y pluralismo, sino una fuerte e inoculable tensión entre el Vaticano, más algunos obispos que secundaron su política, y una buena mayoría de obispos latinoamericanos.

Esta tensión específica va más allá incluso de posturas idcológicas y teológicas y se expresó en la clara imposición del Vaticano sobre la conferencia, a diferencia de lo ocurrido en Medellín y Puebla. El Vaticano impuso los tres presidentes de la asamblea —quienes, además, son de reconocida trayectoria conservadora-, controló la comisión de redacción, trastocó el tradicional modo de proceder ver-juzgar-actuar en la preparación de los texios por el de juzgar-ver-actuar (sobre lo que volveremos, pues en ello está en juego mucho más que un cambio del orden de la palabras), impidió que el excelente texto de la Secunda Relatio e incluso el más moderado Documento de Trabajo sirviesen realmente de base para las discusiones. Además, en ocasiones importantes y simbólicamente significativas se notó una fuerte tensión entre la presidencia y la asamblea, como en la misa de petición de perdón (a la que no asistieron los dos primeros presidentes) y en la petición de que la asamblea como tal escribiera una carta felicitando a Rigoberta Menchú por la concesión del Nobel en esos dias, petición que fue rechazada por la presidencia, dando como razón el temor a que la carta de la asamblea pudiera ser manipulada ideológicamente.

Estas y otras muchas cosas muestran inocultablemente la tensión 'entre el Vaticano y la Iglesia latinoamericana, tensión, por cierto, nada nueva, pues ya afloró en las instrucciones vaticanas de 1984 y 1986 sobre la teologia de la liberación, en la intervención vaticana de la CLAR y, en general, en la política vaticana de nombramiento de obispos, de modo que la generación de obispos

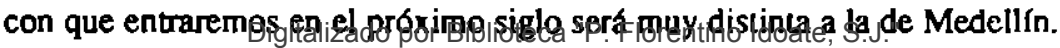

Universidad Centroamericana José Simeón Cañas 
Santo Domingo no ha sido una excepción. En conjunto parece ser que la mayoría de los obispos latinoamericanos no vieron como un bien el servilismo -aunque aceptan la obedicncia responsable-, ni se dejaron manipular con la facilidad deseada por la presidencia, lo cual se mostró en muchas discusiones y votaciones en el aula y en algunas declaraciones fuera de ella. Pero a la postre tuvieron que inclinarse a las exigencias vaticanas. En el método, en comisiones claves y en la orientación teológica fundamental, la mayoría tuvo que ceder a la presión vaticana.

Este autoritarismo y centralismo eclesiales no hace ningún bien a la Iglesia. Desde un punto de vista intraeclesial no refleja sino que dificulta grandemente in actu cl que la communio sea la máxima expresión del misterio eclesial, a pesar de tantas recientes advertencias vaticanas en su favor. Ni la Iraternidad ni la libertad de los hijos e hijas de Dios se ven rellejados en este modo de proceder. Y por lo que toca a la asamblea misma de Santo Domingo es evidente que la imposición vaticana no sólo se hizo notar desde el principio, sino que determinó la dirección de la asamblea, hizo gastar innumerables energías, que hubieran sido mejor empleadas en redactar un buen texto, y, lo más importante, dejó un mensaje de tristeza para las iglesias locales y nada digamos de la periferia: el miedo a la libertad y a la creatividad, el miedo a ver la realidad y al mismo Dios desde lo distinto y desde la periferia, el miedo a ser ellas mismas.

Desde el punto de vista de la evangelización de la cultura, no deja de animar, por una parte, que los obispos de la periferia, con sencillez y firmeza, hayan intentado no dejarse imponer por el centro. Pero por otra, el ambiente de imposición y la imposición real que prevaleció en Santo Domingo ha sido otra oportunidad perdida de evangelizar a un mundo muy interesado en autoritarismos y centralismos; oportunidad perdida, por ejemplo, para decir a las potencias del norte, a las Naciones Unidas y a los foros internacionales que recojan, respeten y animen la voz de la periferia y no le impongan - como ocurre casi siemprelo que tiene que hacer.

Hemos comenzado por aqui por aquello de la honradez con lo real, pero también porque esta tensión entre imposición romana y creatividad latinoamericana determinó la conferencia y la ha hecho no sólo ambivalente -la presencia, en teoría, de dos valores, jerarquía y base-, sino realmente ambigua, porque ha puesto - por ahora - punto final a todo el proceso alrededor de Santo Domingo y también porque ilustra la necesidad de decisión y audacia para poner por obra lo mejor del texto sin contar con viento favorable del Vaticano.

Pero hay que terminar con una reflexión final, también verdadera y posiliva. Si hubo imposición, si se gastaron muchas horas en discusiones y peleas, es que hay identidad en la Iglesia latinoamericana, es que Medellín no ha muerto. No goza ahora esa Iglesia de viento a favor, pero ahí está. Con medidas administrativas se querrá neutralizarla, pero la pastoral, la teología, la evangelización y la

Universidad Centroamericana José Simeón Cañas 
fe pueden todavía contar con esa identidad. Es triste que haya tenido que aparecer sub specie contrarii, en resistencia a la imposición, pero ha aparecido y se puede poner a producir.

\section{Pedir perdón con seriedad}

La historia -el quinto centenario- y la geografía -Santo Domingo, la antigua isla de La Española - exigian una palabra de la Iglesia sobre lo ocurrido entonces y a lo largo de cstos cinco siglos. El ambiente, pues, hacía ineludible tomar postura sobre si pedir o no perdón a los indígenas supervivientes, pues razas y pucblos enteros, religiones y culturas quedaron exunguidos o fueron aniquilados por los conquistadores, y a los negros traídos de Africa, en forma infame - como mercancía- en una de las mayores y más crueles aberraciones que recuerda la historia.

No cabe duda de que, aun sin caer en leyendas negras, hubo un inmenso pecado de lesa humanidad, que se convirtió, además, en pecado original y originante. Pues bien, ese pedir perdón, lan indispensable para evangelizar la cultura y purificar el aire contaminado, encubridor, prepotente y despreciativo hacia el "otro", no lo han hecho gobiernos, ni ejércitos, ni empresas transnacionales, y de alguna manera sí lo ha hecho la Iglesia.

Se pidió perdón con ambigüedades, ciertamente. Unos obispos - los que viven con indigenas y negros, quienes hasta el día de hoy llevan consigo la marca de la opresión, de la indignidad y del sufrimiento de siglos- lo han hecho con sinceridad, y otros no lanto - el cardenal arzobispo de Santo Domingo, presidente del CELAM y segundo vicepresidente de la Asamblea, no accedió a que se celebrase la misa del perdón en su catedral. Y hay que recordar lambién que, aunque quedó bastante claro por qué pecados se pedía perdón, no quedó sicmpre tan claro quiénes fueron los pecadores de hace cinco siglos: si los conquistadores y sólo ellos o también los eclesiásticos. Nada, pues, de triunfalismos.

De toda formas, el que Juan Pablo II pidiera perdón en Santo Domingo y lo volviese a hacer a su regreso en Roma, el que lo hicieran los obispos en una eucaristía y lo introdujesen en algunas partes del texto es en sí mismo importante. En el mundo del norte, pecador e hipocrita, que piensa no tener que pedir perdón a nadie, ni por la muerte violenta que ha generado en Vietnam, Afganistán o Irak, en El Salvador, Guaternala, Grenada o Panamá, ni por la muerte lenta del sur del planeta, pedir perdón es cosa buena y purifica el aire que respiramos.

Muy bien está, pues, el perdón de Santo Dormingo, pero es también necesario - para que con él se pueda evangelizar las culturas- que todos, el papa, los obispos, sacerdotes, religiosos y religiosas lo hagan con convicción real, no 
como para salir del trance, con propósito de enmienda y con espíritu de reparación hacia los negros e indígenas, lal como lo pedía Monseñor Leonidas Proaño en su lecho de muerte: que la Iglesia repare todo el mal que ha hecho a los indígenas. Es también necesario que la petición de perdón no se quede sólo en el pasado, sino que la Iglesia tenga la honradez de pedir perdón en y por el presente, sin lo cual no tendrá credibilidad al pedir perdón por el pasado. Y por último es necesario que el perdón se pida con la disponibilidad real a ser perdonado, pues, aunque parezca paradójico, eso es lo más difícil, ya que, en las conocidas palabras de Karl Rahner, "sólo cl perdonado se sabe pecador". Pero eso es también lo más cristiano, pues entonces el perdón se convicrte en don y gracia, en recibir inmerecida $\mathrm{e}$ inesperadamentc la acogida quc otorgan las víctimas, los olendidos.

Introducir en este mundo la humildad y la honradez de pedir perdón y la disponibilidad a recibirlo como gracia no es pequeño beneficio que la Iglesia puede hacer a este mundo. De esta forma pucde cvangelizar una cultura de la hipocresía y de la prepotencia. En esto, tímidamente, Santo Domingo abrió un camino que la Iglesia tiene que proseguir y que lo ofrece a todos.

\section{El pecado del mundo y el pecado de la Iglesia}

En el mundo occidental hay una cierta tesis oficial según la cual, aunque existen graves problemas, el mundo va bien o, por lo menos, va mejor que antes. Con la caida del este y de muchos regímenes militares, con la paulatina democratización, aunque esto sólo ocurra, muchas veces, formalistamente, y la imposición - sin oposición- del neo-liberalismo económico, hemos llegado "al final de la historia". Y esto se repile aunque la experiencia cotidiana -y un informe técnico de las Naciones Unidas - muestra que, al menos a las inmediatas, las cosas van a peor en el mundo como totalidad, y las promesas de que pronto mejorarán no es creible para las mayorías después de infinilas promesas semejantes.

En este contexto, Santo Domingo, siguiendo a Medellín y Puebla, ha hecho dos cosas importantes: un ejercicio de honradez fundamental por lo que toca a la verdad de la realidad y a su exigencia élica. Por lo que toca a lo primero ha vuelto a denunciar la atroz situación de miseria e injusticia y ha criticado el neoliberalismo económico no sólo como intento de solución muy poco humano y muy insuficiente, sino como agudizador de la miseria. Muchos obispos fuera del aula y el mismo texto lo afirman. Estamos mal y vamos a peor, dicen: "creciente empobrecimiento", "las estadísticas muestran con elocuencia que en la ultima década las situaciones de pobreza han crecido tanto en números absolutos como relativos", "la política de corte neoliberal profundiza aún más las consecuencias negativas". Dicho todo esto en la tradición de Puebla, "tenemos que alargar la lista de rostros sufrientes".

Digitalizado por Biblioteca "P. Florentino Idoate, S.J."

Universidad Centroamericana José Simeón Cañas 
Cuánto caso haga el mundo en esto a Santo Domingo, no lo sabernos, pues ese mundo que aplaudió a Juan Pablo II por su contribución a la caída del este, lo ignoró, como ya hemos dicho, cuando denunció la guerra de Irak. Lo mismo podrá ocurrir ahora con Santo Domigno, que muy bien podrá ser ignorado en esa denuncia fundamental del pecado de injusticia institucionalizada. En sí mismo, sin embargo, es evangelizador en una cultura de la indiferencia y de la injusticia el que Santo Domingo haya vuclto a decir la verdad y no haya querido cooperar al encubrimicnto y a la mentira institucionalizada de que ahora el mundo va por buen camino - una vez desaparecido el socialismo real- si es que hace caso al norte.

Por lo que toca a lo segundo, Santo Domingo ha vuclto a reiterar la opción por los pobrcs, preferencial, sí, basada en la Palabra de Dios y no en ideologías, pero opción al lín y al cabo, y, en palabras de Juan Pablo II, opción "firme e irrevocable", que da "la medida de nuestro seguimiento de Cristo". De ahí también que, ulópicamente y sin mucho que aportar desde un punto de vista técnico, los obispos ofrezcan como altcrantiva al neo-liberalismo una "economía de la solidaridad", es decir, una economía que tenga directamente ante sus ojos -y no sólo como posible subproducto positivo del neo-liberalismo, que en directo siempre favorece a los más pudientes - la posibilidad de vida de las mayorías.

La denuncia de la injusta pobreza y la opción por los pobres son indudablemente evangelizadoras en nuestro mundo, pues, por una parte, hasta los términos "justicia" e "injusticia" están desapareciendo del vocabulario oficial de esc mundo - como si los males y sus soluciones fuesen ouros, y como si fuese de ignorantes o de mala educación mencionarlos-, y, por otra, la opción por los pobres suena a macabro eu[emismo, cuando casi ninguna de las naciones llega a cumplir con la entrega del 0.7 por ciento para ayudar a los países subdesarrollados. Sin embargo, tampoco aquí caben Ios triunfalismos.

Aunque algunos obispos, en la línca del cardenal Ams, por ejemplo, han comunicado personalmente con gran vigor estas denuncias y desenmascaramientos, los textos no tienen el pathos que tenían en Medellín y Puebla, puede ser por la falta de novedad, pero también porque no se vislumbra la decisión de luchar por la justicia y de correr los riesgos de la denuncia que se hacia presente en textos anteriores. Estrictamente hablando, los textos describen la tragedia en que vivimos, pero no son textos de denuncia, menos de desenmascaramicnto y mucho menos de confrontación con los responsables de la tragedia que describen. $Y$ hacer eso, aun cuando lodo el mundo desea disminuir el nivel de confrontación, es cosa todavía muy necesaria. Por ponerlo en un solo ejemplo, el batallón Atlacatl, tristemente conocido por la masacre de El Mozote y el asesinato de los jesuitas, cntrc otros, todavía sigue aireando su consigna que dicc "Por la patria y con Dios". Ante estos cosas, no basta con denunciar la realidad, sino que hay que confrontarse con quicnes la han conver- 
tido en realidad trágica.

Además, sea cual fuere el grado de audacia de los textos, a nadie se le escapa que está desapareciendo -y ello parece ocurrir muy conscientemente desde el Vaticano-- la generación de obispos que ponfan en práctica esas palabras y llegaban a serias confrontaciones con los poderes públicos. No es que ya no los haya en absoluto, por supuesto, pcro los gobiernos, los ejércitos y las oligarquías, saben muy bien que cada vez quedan menos obispos como don Sergio, como monseñor Romero, como Proaño, como don Heldcr... Por ello, palabras sobre injusticia y opción, casi idénticas a las de textos anteriores, dicen hoy menos que aquéllas. Contra Mcdcllín se alzó enseguida el vicepresidente estadounidense Nelson Rockefcller y contra Puebla, los asesores de Ronald Reagan. Hasta ahora no sabemos que los poderes de este mundo se hayan sentido amenazados o afectados por Santo Domingo y si se alzarán contra él, o si. una vez caído el este, poco les importa la crítica que provenga de instancias religiosas.

Y quisićramos añadir también que, si denunciar cl pecado de injuslicia y optar por los pobres es evangelizar la cultura, no lo es el ignorar cl pecado dentro de la misma Iglesia, ignorar su aporte al pecado del mundo, por acción y sobre todo por omisión. El problema viene de muy antiguo, ya lo sabemos, pero hay que recalcarlo. Tambićn para la mayoría de obispos en Santo Domingo, y nada digamos en el Vaticano, parece que los males del mundo -injusticia, dictaduras, corrupción, engaños...- siempre provienen de "los otros", comunistas, dictaduras militares, capilalistas incluso (como lo eran antes los racionalistas, protestantes, incrédulos y paganos...) y que todos esos males se hubieran obviado si se hubiera hecho caso a la Iglcsia. Se da aquí no sólo un triunfalismo sin fundamento, sino una actitud poco o nada evangelizadora, pues la Iglesia pierde credibilidad si sólo denuncia lo de afuera sin reconocer, al mismo tiempo, con sinceridad y humildad lo de dentro.

Ese reconocimiento del propio pecado no ocurrió en un grado mínimamente notable en Santo Dorningo. La Iglesia, en efecto, ve mucho más cl pecado fuera que dentro de ella, y cuando mira a su interior nota los pecados, debilidades o peligros en los laicos y en las laicas más que en los sacerdotes, en los religiosos y en las religiosas, y en éstos más que en la jerarquía, que parece estar inmune por principio a cualquier limilación de lo humano.

No abogamos, por supuesio, ni por un imposible angelismo cclesial ni por un masoquismo paralizador, pero hay que ser conscientes de que se da aquí, una vez más, una oportunidad perdida de cvangclizar la cultura. En un mundo hipócriba que no quierc pedir perdón por la opresión a que somcle a dos tercios del planeta, que hace pasar incluso por grandeza histórica lo que es muchas veces depredación y desurucción de ouros pucblos, sería muy evangclizador —más que cualquier palabra - que tambićn la Iglesia reconociera con sencillcz. sus propias

Digitalizado por Biblioteca "P. Florentino Idoate, S.J."

Universidad Centroamericana José Simeón Cañas 
limitaciones y pecados.

\section{El reconocimiento del "otro"}

El mayor aporte teórico de Santo Domingo está en haber abordado y reconocido al "otro" con mayor claridad que en anteriores documentos eclesiales; en concreto en haber reconocido a la mujer, al indígena y al negro. $Y$ es que, si difícil es el reconocimiento del "pobre" más difícil puede llegar a ser el del "otro", aunque con gran frecuencia ambos coinciden en una misma persona o grupo. El "pobre" expresa y es en sí mismo una terrible exigencia ética y teologal, ciertamente, pero el "otro" llega a tocar las raíces mismas no sólo de la liturgia, sino de la mediación de la fe, del dogma, de la teología, de la doctrina de la Iglesia, etc. El "otro" nos introduce rcalmente no sólo en lo distinto, sino en lo desconocido.

Las razones por las que los obispos se fijaron en el otro son variadas. Por pudor y por responsabilidad algo serio habia que decir en el quinto centenario sobre indígenas y negros. Obispos hubo que venian a decir que no podrían volver a sus diócesis sin un texto serio en estos asuntos. Por lo que loca a la mujer es umbien evidente que no se puede seguir como hasta ahora ni la Iglesia puede desentenderse de estos asuntos o trivializar la problcmática con enfoques simplistas. De hecho, sobre estos temas se escribieron los textos más vigorosos, aunque no fuese más que por su novedad dentro de la Iglesia.

Cuál sea la operatividad de estos textos se mostrará en si se ponen en verdad a producir, si los obispos y agentes de pastoral se inculturan realmente en esas culuras del "otro", si se abren a ellas, si dan y reciben de ellas, y si el Vaticano anima todo ello o por lo menos no lo impide. En una palabra, si la Iglesia supera - haciendo contra ellos - los seculares hábitos de colonialismo, paternalismo, masculinismo y clericalismo.

Si a todo esto que hay que superar se aflade lo que la Iglesia liene que aprender, entonces las cosas no son nada láciles, pues tendrá que aprender aquello sobre lo que piensa saber ya sulicientemente. Si en la actualidad la posible ordenación de la mujer está causando inmenso revuelo, aunque no parece exisitir ninguna dificultad dogmática insuperable, y si es presentada, por ahora, como problema sin solución, ¿qué decir de una liturgia, una élica, una dogmática basadas en lo "otro", es decir, en lo realmente desconocido, en lo que por definición no es manejable desde conceptos y prácticas ya adquiridas y consueludinarias?

$Y$ es que lo "otro" es una eficaz mediación de lo que en el misterio de Dios hay de "alteridad". Ponemos ante lo otro, dcjândole ser otro, es una forma eficaz de ponemos ante el misterio de Dios. Y eso, ayer como hoy, no es fácil. Y sin embargo, eso, y no un puro folklorismo litúrgico, como lo advierte don Pedro Digitalizado por Biblioteca "P. Florentino Idoate, S.J."

Universidad Centroamericana José Simeón Cañas 
Casaldáliga, es lo que está en juego al aceplar la rcalidad de la mujer, del indígena, del negro, del mestizo, del "otro".

Hay aquí, pues, avances importantes y, a la vez, difíciles. Visto desde su impacto evangelizador en la cultura, por lo que loca al reconocimiento de la mujer habrá que decir que el mundo ha evangelizado a la Iglesia antes que ésta a aquél; y que la Iglesia, por lo tanto, debe en esto aprender del mundo y agradecérselo. Por lo que toca al indígena y al negro, la Iglesia - si realmente los acepta, los valora y los acoge- estará evangelizando una cultura que todavía hoy - a pesar de las declaraciones universales y democráticas de igualdadignora, oprime y desprecia al otro, lo desea mantener geográfica y antropológicamente lejano; una cultura en la que recientemente, en varios países del norte del planeta, están rebrotando incluso graves y alarmantes signos de xenofobia.

Bueno es, pues, que Santo Domingo haya hablado sobre el "otro", pero es necesario que la Iglesia lo defienda en su pastoral real y que corra los riesgos necesarios por ello.

\section{El retroceso en teología}

Por lo que toca a la teología hay una marcha atrás, y to lundarnental del retroceso consiste en el modo de proceder tcológico, el método. La realidad histórica, en efecto, no es vista ya como signo de los tiempos en sentido estrictamente teologal, es decir, como lugar en el que el mismo Dios puede decir su palabra y en el que puede estar presente él mismo, en cuanto Dios. Esto supone una importante marcha atrás con respecio al Vaticano II, que enunció la realidad e importancia de los signos de los tiempos para la misión de la Iglcsia, y con respecto a Medellín y Puebla que los escrutó in actu y sobre los que basó su rellexión teológica.

Como ya hemos dicho, en Santo Domingo la presidencia impuso cl esquema de juzgar-ver-actuar, que viene a decir que primero hay que hacer teología, después hay que ver cómo está el mundo y por úlumo hay que aplicar aquélla a éste. Se quiere, por lo tanto, "juzgar" desde Dios algo que todavía no se ha "visto". Y por lo que toca a los textos bíblicos cilados, se quiere ver a Dios en dichos textos del pasado sin haber visto a Dios en la realidad del presente.

Es indudable que la relación entre ver y juzgar, entre realidad y teología es dialéctica. No hay que pensar por lo tanto que del puro ver provendrá mecánicamente un correcto juzgar, que de la pura experiencia surgirá mecánicamente la teología. Pero, dentro del necesario círculo hermenéutico, hay que mantener lo que es fundamental para toda teologia cristiana, basada en un Dios que se ha hecho historia: no puede haber teología sin realidad histórica previa, no se puede encontrar a Dios en textos del pasado sin auscultar su realidad en cl presente.

Digitalizado por Biblioteca "P. Florentino Idoate, S.J."

Universidad Centroamericana José Simeón Cañas 
Esto que aquí está dicho en forma abstracta tiene graves repercusiones concretas en la teología de Santo Domingo. Una de ellas es que la cristología, proclamada como vertebradora fundamental de todo el documento, no está basada en Jesús de Nazaret, sino en un Cristo abstracto, en coherencia con la lógica descrita: se juzga a Jesús como el Cristo, sin haber visto antcs la rcalidad de ese Cristo que es Jesús. De esa forma desaparece el Jesús histớico, presente en Medellín, la Evangelii Nuntiandi y Puebla, quizás más en forma de dinamismo que en textos muy concretos; presente ciertamente en las comunidades más comprometidas y en las que ha habido más mántires, y prescnte por supucsto en la teología de la liberación. En Santo Domingo, sin embargo, se ha preferido comenzar proclamando al Cristo de la fe más que viendo a Jesús de Nazaret.

Otra consecuencia de este modo de proceder es que los mejores textos del documento no son -irónicamente- los teológicos, en lo cual los obispos debieran ser expertos, sino los históricos. En efecto, los textos más estrictamente teológicos con que comienzan todos los capítulos son reconocidamente desleídos y carecen de inspiración. Cierto es que se citan en ellos pasajes de la Escritura, concilios y papas, pero aunque éstos posean la autoridad dcl magisterio y algunos de ellos son inspirados, no son inspiradores, si se nos permite la ironía.

Por expresarlo de la forma más radical, "que Dios nos ha arnado" es un texto central que expresa una esencial y consoladora verdad de la fe. Pero si ese texto no se pone en el contexto de una realidad concreta, puede sonar a cosa puramente espiritualista, a rutina por lo tanto, sin capacidad de movilizar las fuerzas del espíritu, mientras que si aparece como culminación de un relato sobre las víctimas de este mundo, su amor martirial y su esperanza, entonces el mismo texto puede expresar la solidaridad y ternura de Dios hacia ellas, y entonces el texto se convierte en buena noticia.

Este modo de proceder teológico que acabamos de analizar es algo que en directo sólo concieme a la Iglesia y, a lo sumo, a la academia. Sin cmbargo, pensamos que tienc también un potencial evangelizador en cl ambiente en que nos movemos, pues en nuestro mundo se procede con frecuencia con a prioris ideológicos que no se contrastan con la realidad. Con mucha frecuencia "es verdad" y "es solución" aquello que se ha decidido de anternano que lo sea, pase lo que pase en el mundo. Así, es verdad la "democracia", dicen unos. Es verdad "el neoliberalismo", "la necesidad de ejércitos", o la "modernidad" o la "postmodernidad" (aunque esta última, por definición, no pueda autoproclamarse como verdad absoluta).

Si se trata de buscar un paralclismo entre este fenómeno y la fe de la Iglesia se argüirá, sin duda, que no puede equipararse a la verdad de ideologías o instituciones humanas la verdad de la fe; se dirá que la fe contiene la verdad con independencia de lo que ocurre en el mundo... Pero, sin entrar ahora en una discusión teórica sobre ello, pasioralmente al menos es muy importante que lo 
que podemos llamar verdad genérica de la fe se torne verdad concreta, y por ello verdad actuante y relevantc, y eso ocurre cuando se la constrasta con la realidad.

La relevancia pastoral de la fe se jucga en la capacidad que ticne de ser iluminada (verificada y verdadeada, si se nos permite la expresión) por la realidad histórica. Y si eso se dice de la fe, a fortiori debe decirse de la leología. Con todo ello queremos decir que una forma de vivir y comprender la fe y la teología, abiertas a la realidad, contrastadas con la realidad y enriquecidas por la realidad —el comenzar, aunque sólo sea lógicamente, con el "ver" la realidades también una forma de evangelizar la cultura, de superar a prioris y dogmalismos, tan claramente percibidos ahora en los cuestionados mélodos de cristiandad y en los fracasados marxismos dogmáticos, pero igualmente necesario para superar los neo-liberalismos, modernismos, pragmatismos, posumodemismos, que tienden a imponerse sicmpre dogmáticamentc.

Si de algo está necesitado cl mundo de hoy es de "ver" la realidad sin manipularla, más aún de "escucharla", pues, como decía Karl Rahner, "la realidad quiere tomar la palabra", y —con Medellín y Puebla - esa palabra se convierte en un desgarrador clamor. Ojalá la Iglesia de Jesús ayude al mundo en esta tarea nada fácil. $Y$, por cierto, si la silenciada y aun vilipendiada teología de la liberación ha producido bienes en nucstro mundo, esto ha sucedido, ante todo. por su honradez en mirar a la realidad, escuchar sus clamores y tratar de responder a ellos.

\section{El silencio sobre los mártires}

La consecuencia más funesta de no comenzar "viendo" la realidad es el silencio sobre los mártires. Cierto es que en reuniones de oración los obispos recordaron a monseñor Romero y a otros mártires latinoamericanos, pero nada de esto puede reparar el silencio increible del texto. Y no se supera ese silencio añadiendo una línea al final del capítulo dedicado al recuerdo de los 500 años de evangelización en que se reconoce "a quienes han llegado hasta el testimonio de dar la sangre por amor de Jesús", pues por la extrema parquedad del texto, por la ambigitedad del contexto histórico — iincluye a los mártires de hoy? - y por el nulo análisis histórico y teológico de hecho can fundamental, más parece una frase afladida para salir con bien de un espinoso trance que honda convicción de la centralidad del martirio.

Por mucho, pues, que traten de explicarlo —peligros de manipulación, cautelas que impone el derecho canónico, conflictos que puede ocasionar a la Iglesia...- nadie entiende, ciertamente en países como El Salvador y Guatemala, que no sólo no se valore grandemente a los mártires, sino que ni siquiera se los mencione. $Y$ es que en América Latina, el martirio no es la anécdoca o la excepción, sino una realidad masiva inocultable: es la novedad, la gracia, la credencial y el sello de la evangelización más genuina que se ha llevado a cabo entre

Universidad Centroamericana José Simeón Cañas 
Medcllín y Santo Domingo. El silencio es, por lo tanto, absolutamente incomprensiblc, altamente sospechoso y, sobre todo, sumamente empobrecedor.

Ignorar a los mártires, en efecto, significa realmente prescindir de los signos de los ticmpos, tanto en cuanto éstos describen aquello que caracteriza una época -el martirio, por su masividad, es lo más novedoso y característico de la historia reciente de la Iglesia en América Latina- como en cuanto expresan, por su calidad, la presencia de Dios entre nosotros. Significa también privarse de un insustituible principio hermenéutico para comprender a Jesús, pues los mártires de hoy - a diferencia de la mayoría de martirios a lo largo de la historia- mueren como Jesús, por la misma causa que Jesús y todo ello porque, estructuralmente, vivieron como Jesús. Significa también desconocer el origen histórico y teologal de la misma Iglesia, nacida realmente tras el martirio de Jesús, en prosecución de la vida de Jesús y con la esperanza de resurrección, es decir, de que Dios ha hecho justicia al mártir Jesús. Significa desaprovechar el principal motivo de credibilidad hoy para la Iglesia, tan importante para anunciar a increyentes el misterio de Dios y para fortalecer en la le a dubitantes, y an decisiva para decir a los pobres que Dios los ama. Significa, por último, ingratitud para con los mismos mártires, privar de consuclo a sus familiares, desconocer a quienes siguen siendo luz y ánimo para las comunidades...

Ya vimos que la Secunda Relatio, en el largo texto anteriormente cilado, procede exactamente de manera contraria, y de esta forma se esclarecen varias cosas: que sí hubo tensión fuerte con el Vaticano y que sí hay divisiones en la Iglesia latinoamericana, pues ni un eco de este espléndido texto ha quedado en el documento final. Pero muestra también que hay grupos de obispos -y muchas comunidades tras ellos- para quienes los mártires, cuando reflexionan sobre ellos en la realidad sangrante de sus paises, son los testigos de la fe y del amor, esenciales $\mathrm{e}$ insustituibles para vivir hoy dicha fe y dicho amor.

El texto cilado, en efecto, obvio y sorprendente a la vez, recuerda y hace central a los mártires y desarrolla una importante teología de por qué hay martirio y de por qué esos martirios son algo central. Este texto y, por supuesto, la realidad que está tras él —el hecho del martirio por amor y el reconocimiento agradecido por parte de los cristianos- sí es buena noticia, sí es evangelización para los pobres de este mundo, aunque cause espanto a los poderosos —en El Salvador todavía le tienen miedo a monseñor Romero y al padre Ellacuría- y aunque -como está predicho en el evangelio de Juan- quienes mataron a monseñor Romero y el batallón Atlacatl que asesinó a los jesuitas, a las dos mujeres y a otros muchos usen y abusen del nombre de Dios y se digan católicos de siempre.

Puede discutirse teóricamente hasta la saciedad en qué consiste la "nueva" evangelización, pero la respuesta debe tener un ingrediente esencial y obvio: en recuperar - novedosamente, si se quiere - la buena noticia que trajo y fue en su Universidad Centroamericana José Simeón Cañas 
propia vida Jesús de Nazaret. Y eso lo recuperan ante todo los mártires. Ellos son en nuestros días quiencs anuncian el reino de Dios a los pobres, quienes les anuncian que la vida, la fralcmidad y la dignidad son posibles, quienes se enfrentan a los ídolos que convierten en víctimas a los pobres y quicnes les dicen que Dios les quicre. $Y$ ellos son los que en nucstros dias re-crcan el evangelio que predicaba Pablo: cl márlir Jesús, crucificado y resucitado. Por cllo, una vez más, es simplemente increible que Santo Domingo no mencionc a los mártires. lo mejor que ha producido la Iglesia latinoamericana, lo mejor que tenemos.

$Y$, además, al no mencionarlos deja de evangelizar la cultura, deja de purificar con la honradez, la compasión y el amor de los márlires el corrompido aire de mentira, indiferencia y opresión de nuestro mundo. En él ni ejércitos, ni gobiemos, ni oligarquías mantienen vivos a los mártires; tampoco lo hacen muchos partidos políticos ni universidades ni medios de comunicación. Así le va a nuestra cultura, descristianizada, deshumanizada. Volver a humanizarla y crislianizarla no es cosa sólo ni principalmente de palabras, sino de imbuirla de la honradez, la compasión y cl anor real de los márlires.

\section{Principios para poner a producir el acontecimiento de Santo Domingo}

Como acabamos de ver, en Santo Domigno soplaron muchos y variados vientos, unos mejores y otros peores. En conjunto, visto todo lo que hemos juzgado como positivo y como negativo, Santo Domingo es [iel reflejo de la situación de la Iglesia universal y de la Iglesia latinoamericana. Lo primero significa que existe un movimento de involución sostenido que parte del centro y encuentra suficientes adeptos en la periferia, unos con buena voluntad según su conciencia, y otros más militantemente. Lo segundo significa que existe todavía un serio forcejeo dentro de la Iglesia latinoamericana por mantener o desvirtuar el espíritu de Medellín.

Visto todo en su conjunto, Santo Domingo no es, ciertamente, motivo de exultación - lo cual se nota en las mismas reacciones episcopales-, pero tampoco debiera ser motivo de abalimiento paralizante, pues también en él se hicieron presentes - aunque no se impusieron casi nunca como debian-vientos evangélicos y latinoamericanos. En nuestra opinión, lo más negativo de Santo Domingo es la tristeza que produce el haber sido una oportunidad perdida, en buena medida, para ahondar más en las tareas eclesiales $y$, sobre todo, para recoger mucho mejor los clamores de la realidad y evangelizar más decididamente la cultura.

Sin embargo, hay que poner a producir a Santo Domingo, porque el acontecimiento da pie para ello y porque lo esperan y lo necesilan los pobres del continente. Para ello hay que buscar algunos principios iluminadores y animadores en dicha tarea, y éstos creemos que hay que buscarlos más fuera que

Digitalizado por Biblioteca "P. Florentino Idoate, S.J."

Universidad Centroamericana José Simeón Cañas 
dentro de la misma reunión. Y por eso también hablamos más bien de principios para poncr a producir a Santo Domingo que de principios interpretativos intrínsecos a Santo Domingo.

Esto último es realmente difícil porque las diferencias y tensiones fueron tales que no nos parece posible encontrar algo que unifique suficientemente el acontecimiento y el texto. Cicrto es que también en Pucbla hubo divisiones y tensiones, pero la "opción preferencial por los pobres" muy pronto se conviruó de hecho -y, además, tenía en su favor la posiblidad de serlo de derecho- en principio interpretativo de todo el texto. Pero nada de esto hay en Sanio Domingo, algo que se imponga por sí mismo como principio unificante del todo. Y si se aduce que la cristología scría el tal principio interpretativo - como de alguna manera se pretendió desde el Vaticano- su grado de abstracción es tal que tampoco puede fungir en tal sentido.

Por ello, si no dentro del mismo acontecimiento, habrá que encontrar fuera de él principios que puedan, si no unificar lan dispar evento, sí poner a producir lo mejor del acontecimiento y del texto. Y éstos nos parecen ser los siguientes.

1. Para poner a producir eficazmente a Santo Domingo hay que tomar en serio lo que también alli se afirmó: que debe ser considerado en continuidad con Medcllín y Pucbla. Esto no significa primariamente que se cotejen los textos o incluso que se haga una sinopsis de las tres conferencias, lo cual ciertamente será muy útil y provechoso. Lo que esto debe significar, en nucstro opinión, es más bien reconocer que la Iglesia latinoamericana debe vivir todavia del espiritu de Medellín, y ello no por una decisión voluntarista, sino porque todavía no hay otro mejor. No quiere eslo decir que no hay nuevas agendas para la Iglesia, por supuesto, pero sí que es muy peligroso plantear la necesidad de novedad, cuando en buena parte ya es realidad en la Iglesia desde Medellin.

En concreto, cuando Santo Domingo exige la evangelización de las culturas -y ojalá lo haga la Iglesia- y la necesidad de abordar la cultura de indígenas y negros como desafio para la Iglesia, no debiera olvidar que Medellín ya proclamó esa necesidad fundamental al exigir la encarnación de la Iglesia en la realidad histórica. No es que ambas cosas sean exactamente lo mismo, pero tampoco son tan dispares, y lo que todavía enserta Medellín es ante todo el movimiento real hacia la encarnación entre los pobres como modo fundamental de evangelizar la cultura latinoamericana, por una parte, y de inculturarse la Iglesia, por otra.

Y algo semejante hay que decir de la "nueva evangelización". Esta comenz6 ya en Medellín, donde, por cierto, se fraguó la expresión antes de que la popularizara Juan Pablo II, y en comparación con la novedad de entonces la que ahora se pide palidece. Se pide ahora, en efecto, que la evangelización sea nueva en su expresión, en sus métodos y en su ardor, pero, curiosamente, no se replantca lo 
que en sí misma es la evangelización. $Y$ eso es precisamente lo que hizo Medellín: no abordó tanto la novedad de las cosas que rodean y acompañan a la evangclización, sino que abordó simplemente y centralmente lo que es evangelizar. Y añadamos que Puebla dio también el paso decisivo, no superado todavia en la nueva evangelización de ahora, al afirmar que no sólo hay que evangelizar, sino que hay que dejarse evangelizar -con agradecimiento, humildad y gozo- por los pobres.

2. Aunque en este artículo nos hemos fijado más en el acontecimiento que en los tex los de Santo Domingo, digamos una palabra también sobre ellos y sobrc cơmo ponerlos a producir. En general, muchos, tambiên muchos obispos, han reconocido que muy buena parte de los textos son muy flojos, especialmente los de la primera mitad del documento. Ouros textos, como ya lo hemos dicho, son mejores, sobre todo por la novedad que traen consigo.

En nuestra opinión, para hacerlos productivos es necesario hacer una selección, lo cual no tiene nada de manipulación, sino que es puro sentido común, además de que la historia misma se encarga de seleccionarlos, como ocurrió con Mcdellín y Puebla, con independencia de voluntarismos, campañas propagandísticas o incluso manipulaciones. Pero, además de seleccionar los textos más útiles para las comunidades, hay que ponerlos en su contexto real, deben ser, por ello, valorados y puestos en relación con las tareas concretas que propician y exigen, y esto último debe ser apoyado institucionalmentc, es decir, por los obispos que aprobaron los textos.

Si realmente se ponen a producir los textos más novedosos, entonces sí sería cierto - como dicen algunos- que Santo Domingo pudiera suponer incluso un avance de la Iglesia latinaomericana. Pcro eso hay que entenderlo bien. Santo Domingo supone un avance —obvio - en la agenda de la Iglesia, que no puede ignorar por más tiempo la problemática de la mujer, del indígena, del negro, de la ecologia... y esa nueva agenda es la que ha quedado rellcjada en algunos textos. Pero para que se pueda hablar de verdadcro avance, hay que añadir al texto un determinado contexto eclesial, es decir, la decisión de apoyarlo, de ponerlo a producir, y de defenderlo cuando la sociedad -como ocurrirá infaliblemente si la Iglesia se decide a defender a indígenas y negros- reaccione y la persiga.

3. Por último, si nos preguntamos qué cs lo que realmente ha estado en juego en Santo Domingo, que es lo que ha ocasionado discusiones, tensiones e intervenciones vaticanas, y qué es entonces lo que, en nuestra opinión, puede fungir como principio orientador para el futuro, creemos que es la identidad de la Iglesia latinoamericana. En el fondo Santo Domingo ha sido - y sigue siendoun forcejeo sobre lo que significa ser Iglesia, ser cristiano y ser creyente en América Latina.

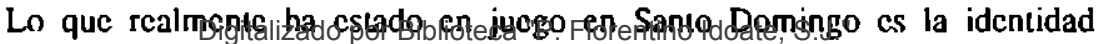
Universidad Centroamericana José Simeón Cañas 
novedosa de la Iglesia latinoamericana. El problema puede ocultarse de diversas formas, aludiendo a problemas de comunión con Roma, peligros o exageraciones en la orodoxia y la liturgia, la teología de la liberación, elc. pero la verdad es que ni los obispos, ni los teólogos, ni las bases tienen problemas graves ni con la comunión eclesial ni con la obediencia leal. Lo que ocurre es olra cosa, es la novedad que ha acaecido en la Iglesia desde Medellin, y que podemos centrar en estas tres cosas.

La primera es, que por primera vez en siglos, la Iglesia latinoamericana ha llegado a ser ella misma. En el proceso histórico de los últimos treinta años, la Iglesia se ha hecho a la vez latinoamericana y cristiana. La realidad latinoamericana llevó a la mejor comprensión y puesta en práctica del evangelio, y éste llevó a la mejor comprensión y acción sobre la realidad histórica. El hecho de que, por primera vez, ser cristiano y ser latinoamericano no supongan algún tipo de oposición, sino de enriquecimiento mutuo es la mayor novedad de nuestro tiempo. Eso, a la vez, ha significado gran creatividad y también gran conflictividad, y a eso le han temido algunos obispos de aquí y del Vaticano. Lo primero que ha estado en juego, pues, ha sido la latinoamericanización de la Iglesia y el forcejeo por mantener o diluir dicha latinoamericanización

La segunda, relacionada con la anterior, es que por primera vez en siglos la Iglesia latinoamericana ha sido socialmente relevante de acuerdo al evangelio. No se ha predicado fundamentalmente a sí misma ni se ha defendido a sí misma como instilución ni ha buscado defender antiguos privilegios. Más bien, como Jesús, ha tenido ante sus ojos al mundo de pecado y ha querido transformarlo en la utopia del reino de Dios. Y esto también es lo que ha estado en juego en Santo Domingo: si mirarse a sí misma o a este mundo de pecado y de esperanza. $Y$ por ello hemos dado decisiva importancia al análisis del martirio en la Iglesia latinoamericana, presente en la Secunda Relatio y ausente en Santo Domingo, porque el martirio es la prueba más inequívoca de tomar en scrio al mundo rcal, cargar con su pecado para bajar de la cruz a los crucificados.

La tercera es que la evangelización se ha dirigido al interior de la Iglesia, por supuesto, pero novedosamente también hacia el mundo, y no sólo tratando de "cristianizarlo" en la superficie, sino de humanizarlo, introduciendo en él los valores más humanos, que son los más divinos y los que Jesús expresó en su propia vida: honradez, libertad, fratemidad, acogida al otro, etc. De esa manera es como la Iglesia va transformando en reino de Dios, a través de la evangelización de la cultura, la realidad en que vivimos. Pero hay que recordar que para ello la Iglesia debe ser, y así ha ocurrido muchas veces, sociedad de contraste, es decir, que introduzca verdad, humildad, compasión, en un mundo y contra un mundo de mentira, prepotencia, desinterés, crueldad. 
En este artículo hemos usado la métafora del viento para orientar nuestra reflexión. Siguiendo la metáfora podemos concluir diciendo que Santo Domingo no ha sido cicrtamente un vendaval, como "la ráfaga de viento impetuoso" de pentecostés. Visto todo en su conjunto, vivimos en una Iglesia en la que, después de que el concilio abriera sus ventanas, éstas se están volviendo a cerrar y el aire se ha vuelto a enrarecer. Pcro en Santo Domingo y, sobre todo, en la realidad cotidiana de las iglesias latinoamericanas persiste, digamos, la brisa de Medcllín, simbolizada en la Secunda Relatio. Y en muchos momentos de compromiso y esperanza, sobre todo los martiriales, esa brisa se convierte en vendaval, y en cualquier caso, contra viento y marea, muchos siguen adclante.

No es por terminar rutinariamente ni por hacer de la necesidad virtud, decir entonces que está en manos de la Iglesia latinoamericana poner a producir lo mejor del acontecimiento de Santo Domingo y de sus textos. Y no lo es porquc, como hemos tratado de exponer, allá soplaron muchos y variados vientos, y también vienlos positivos. Si con tantos poderes en su contra, políticos, cconómicos, culturales, militares, religiosos, a veces también eclesiales, hay cristianos que siguen caminando según la nueva identidad de la Iglesia, según el espíritu de Medellín, entonces es que el Espíritu de Jesús y el Espíritu de Dios siguen actuando. $Y$ con ese Espíritu se puedc seguir adelante. 